\title{
On the Cover of this Issue: Mechanical Behavior of a Dissimilar Metal Weld Interface by G. Ben Salem, E. Héripré, P. Bompard, S. Chapuliot, A. Blouin, and C. Jacquemoud
}

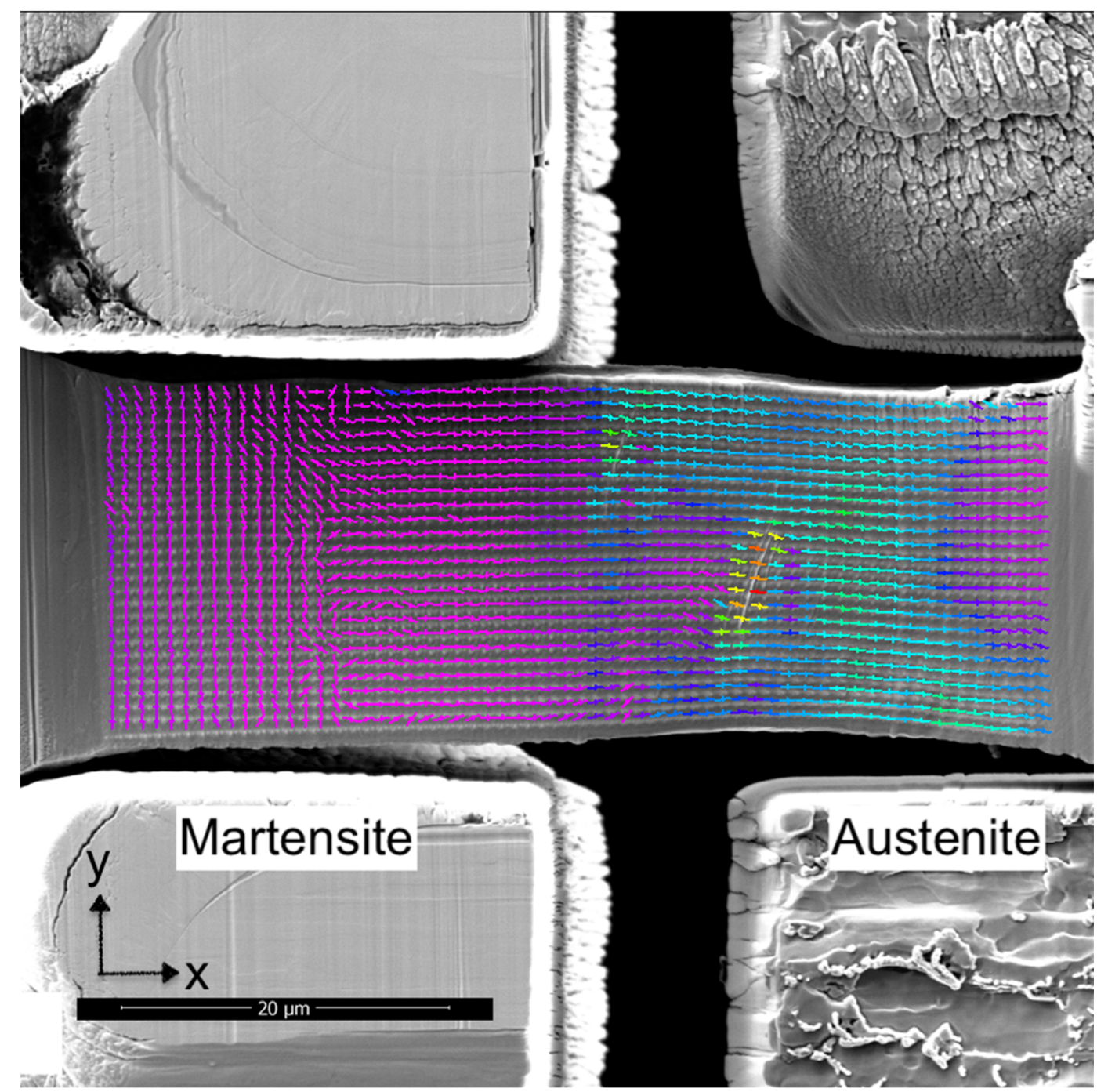

Publisher's Note Springer Nature remains neutral with regard to jurisdictional claims in published maps and institutional affiliations. 